
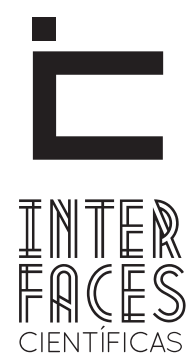

DIREITO

\title{
A NOVA HERMENÊUTICA CONSTITUCIONAL COMO GENUÍNA HERMENÊUTICA DE DIREITOS HUMANOS
}

Karyna Batista Sposato ${ }^{1}$

\section{RESUMO}

0 principal objetivo deste trabalho é demonstrar que os tratados internacionais de direitos humanos dos quais o Brasil é parte, ingressam no ordenamento jurídico interno com força normativa constitucional, como se emendas ao texto constitucional fossem. Isto se depreende de uma interpretação ampla e sistemática do artigo $5^{\circ}, \S 2^{\circ}$ da Constituição Federal de 1988, em busca de conferir a maior eficácia possível à Constituição. Desta confluência entre o direito internacional e o direito público interno configura-se uma verdadeira hermenêutica de direitos humanos que articula as duas dimensões de proteção: a esfera doméstica e a
Eduardo de Abreu Lima Sobrinho²

internacional, ambas essenciais em vista dos desafios contemporâneos colocados ao desenvolvimento. Adotando, por fim, uma perspectiva critica dos direitos humanos, assinala-se a intrincada relação entre desenvolvimento e pleno respeito aos direitos humanos, com especial ênfase aos direitos econômicos, sociais e culturais (DESC).

\section{PALAVRAS-CHAVE}

Hermenêutica Constitucional. Tratados Internacionais. Abertura Constitucional. Direitos Humanos. 


\section{ABSTRACT}

The main objective of this paper is demonstrating that human rights treats that Brazil has ratified enter in juridical domestic system with constitutional normative force, as amendments to the Constitution were. This is due to a broad and systematic interpretation of the article 5, paragraph 2 of the Federal Constitution of 1988, looking to give maximum effectiveness to the Constitution. This confluence of International Law and the Public Domestic Law sets up a true hermeneutic of human rights with a double dimension of protection: the domestic and the international sphere, both of them are essential to face the contemporaneous challenges to development. Finally, adopting a critical perspective of human rights we show that there is a complex relation between development and the full respect of human rights, emphasizing the economic, social and cultural rights.

\section{KEYWORDS:}

Constitutional Hermeneutics. International Treaties. Constitutional Opening. Human Rights.

\section{RESUMEN}

El objetivo principal de este trabajo es demostrar que los tratados internacionales de derechos humanos en los que Brasil es parte, entre las leyes internas y fuerza normativa constitucional, como enmiendas a la Constitución fuesen. Esto se demuestra por una interpretación amplia y sistemática del artículo 5 , § 2 de la Constitución Federal de 1988 , tratando de dar la máxima eficacia a la Constitución. Esta confluencia del derecho internacional y el derecho público establece una verdadera hermenéutica de los derechos humanos que articula las dos dimensiones de la protección: esfera nacional e internacional, tanto esen- ciales en vista de los desafíos contemporáneos para el desarrollo. Adoptando en última instancia, una revisión de la perspectiva de los derechos humanos, señala la intrincada relación entre el desarrollo y el pleno respeto de los derechos humanos, con especial énfasis en los derechos económicos, sociales y culturales (ESC).

\section{PALABRAS CLAVE:}

Hermenéutica Constitucionales. Tratados Internacionales. Apertura Constitucional. Derechos Humanos. 


\section{NOTAS INTRODUTÓRIAS}

No bojo da reflexão sobre a potencialidade jurídica da Constituição e dos direitos humanos, sobressaem-se questões afetas à hermenêutica constitucional contemporânea, como genuíno mecanismo de implementação dos dispositivos derivados dos tratados de direitos humanos. Tais mecanismos de integração de princípios e regras, advindos de tratados internacionais de direitos humanos ratificados pelo Brasil no ordenamento jurídico interno, configuram um dos caminhos mais emblemáticos para a compreensão do atual sistema constitucional adotado e sua força normativa ${ }^{2}$.

Assim, estabelece-se uma nítida conexão entre a consagração internacional dos direitos humanos, por meio de instrumentos jurídicos específicos adotados internacionalmente e seu reconhecimento na ordem constitucional interna, ambos como base essencial para o desenvolvimento em âmbito global e regional.

\section{DIREITOS HUMANOS COMO PROJEÇAO NORMATIVA}

Antes de tratar da chamada abertura constitucional aos tratados de direitos humanos, necessário destacar qual noção de direitos humanos toma-se como ponto de partida.

A noção de direitos humanos, tal qual se concebe hoje é historicamente recente. Sua centralidade no

\footnotetext{
2 Desde Lassale, discute-se se a Constituição jurídica é algo mais que um pedaço de papel, colocando-se em debate que as questões constitucionais não são originariamente questões jurídicas, mas sim questões políticas. Contudo, felizes são as ponderações de Konrad Hesse ao esclarecer que ao lado do poder determinante das relações fáticas, expressas pelas forças políticas e sociais, há também uma força determinante do Direito Constitucional. Significa reconhecer, no escólio do pensamento de Hesse que a Constituição jurídica está condicionada pela realidade histórica, não pode se separar da realidade concreta do seu tempo, contudo não configura apenas a expressão de uma dada realidade, pois em razão de seu elemento normativo também ordena e conforma a realidade política e social. É o que podemos chamar de força normativa da Constituição. (HESSE, Konrad. A Força Normativa da Constituição. Trad. de Gilmar Ferreira Mendes. Porto Alegre: Sergio Antonio Fabris Editor, 1991.)
}

discurso político moderno encontra suas origens nos movimentos de contraposição ao absolutismo e pela extensão da democracia liberal no século XVIII, com destaque ainda mais recente, face à consequências da segunda guerra mundial e a derrota do nazismo. Daí nasce a ideia de que os homens pelo simples fato de serem homens, já possuem uma gama de direitos, que devem ser respeitados e garantidos pelo Estado. Conforme ensina Comparato (1997, p. 29):

\begin{abstract}
O fato sobre o qual se funda a titularidade dos direitos humanos é, pura e simplesmente, a existência do homem, sem necessidade alguma de qualquer outra precisão ou concretização. É que os direitos humanos são direitos próprios de todos os homens, enquanto homens, à diferença dos demais direitos, que só existem e são reconhecidos, em função de particularidades individuais ou sociais do sujeito. Trata-se em suma, pela sua própria natureza, de direitos universais e não localizados, ou diferenciais.
\end{abstract}

Contudo, a universalidade é uma das características dos direitos humanos que com maior facilidade pode levar à abstração, ou a mistificação, a exemplo do que ocorre com a ideia de “bem comum”. Daí, não se pode menosprezar as distintas abordagens conceituais que diferenciam direitos humanos e direitos fundamentais, cujo principal critério diferenciador se refere à positivação de tais direitos.

Paulo Bonavides, utilizando-se dos ensinamentos de Carl Schmitt, determina que na atividade de caracterização dos direitos fundamentais destacam-se dois critérios:

\begin{abstract}
Pelo primeiro, podem ser designados por direitos fundamentais todos os direitos ou garantias nomeados e especificados no instrumento constitucional. Pelo segundo, tão formal quanto o primeiro, os direitos fundamentais são aqueles direitos que receberam da Constituição um grau mais elevado de garantia ou segurança; ou são imutáveis (unabänderliche) ou pelo menos sua mudança dificultada (erschwert), a saber, direitos unicamente alteráveis mediante lei de emenda à Constituição. (BONAVIDES, 2012, p. 579).
\end{abstract}


No mesmo sentido, acrescenta Oscar Vilhena Vieira (2006, p. 36) que direitos fundamentais "É a denominação comumente empregada por constitucionalistas para designar o conjunto de direitos da pessoa humana expressa ou implicitamente reconhecidos por uma ordem constitucional".

Jussara Jacintho, a seu ver, pondera que os direitos fundamentais estão revestidos de três funções: a imperiosidade do reconhecimento da dignidade desta pessoa, a existência de limites impostos ao poder estatal e a afirmação de que os direitos humanos são a base para a interpretação constitucional.

Como instrumento para realização do fim posto - a promoção da pessoa humana em todas as suas potencialidades - os direitos fundamentais hão que exercitar algumas funções, de que são exemplos: a contextualização da pessoa humana na comunidade política com status satisfatório para sua dignidade da pessoa; a segunda função - já mencionada - relaciona-se com os limites impostos ao Estado e ao poder, tanto, quando estes reconhecem e garantem os direitos fundamentais, como, quando a realidade denominada de Estado democrático de direito necessita da materialização daqueles para se legitimar; a terceira função implica que os direitos fundamentais se traduzem e expressam um conjunto de valores e bens que determinam e delineiam a própria condição humana daquela sociedade, assim como é a partir desse conjunto de idéias que a Constituição será interpretada. (JACINTHO, 2009, p. 69).

Todas as posições retromencionadas não resolvem, contudo, "o risco evidente de que os direitos humanos sejam pervertidos no exato momento em que são institucionalizados juridicamente" (FARIA, 2010, p. 152). Pois, como esse autor adverte, "concebidos historicamente como um mecanismo de proteção dos cidadãos contra o arbítrio do Estado, eles podem ser esvaziados na medida em que é o próprio Estado que os regulamenta" (FARIA, 2010, p. 152).

A questão central que se desdobra e com a qual se desenvolve, o ponto de partida está em reconhecer que os direitos humanos não são um produto histórico que confere determinadas potencialidades ao ser humano "desde sempre", mas sim são um produto da práxis humana em um momento da história que outorga ao ser humano certas possibilidades de interferir e interagir com a realidade (MARTÍNEZ, 2008, p. 45)

Na esteira dos ensinamentos de Alessandro Baratta (1999), qualquer abordagem sobre a realidade do homem deve referir-se a pessoas, grupos humanos e povos em sua existência concreta no contexto de determinadas relações sociais de produção. Neste sentido esse autor elucida:

Considerado em um determinado estágio de desenvolvimento da sociedade, o homem é portador de necessidades reais. Desse ponto de vista histórico-social, as necessidades reais constituem um conceito que corresponde a uma visão dinâmica do homem e de suas capacidades. (BARATTA, 1999, p. 71).

Por isso, cabe compartilhar da posição de Baratta de que os direitos humanos constituem a projeção normativa - em termos do que deveria ser - das necessidades que representam potencialidades de desenvolvimento dos indivíduos, grupos, povos. 0 conteúdo normativo dos direitos humanos entendidos com base nessa concepção histórico-social excede, portanto, suas transcrições nos termos da legislação nacional e das convenções internacionais, assim como a ideia da justiça sempre ultrapassa suas realizações na lei e aponta o caminho para a realização da ideia do homem, ou seja, do princípio da dignidade humana (BARATTA, 1999).

Consequentemente, necessário demarcar que tanto os direitos civis e políticos, como os direitos econômicos, sociais e culturais (DESC) são direitos da pessoa humana frente o Estado, e como tais são proteções dos mais débeis frente à violência potencial dos mais fortes, seja no âmbito público, seja no âmbito privado.

Desse modo, cabe referir que o Estado democrático e o constitucionalismo moderno resultam ainda, e inegavelmente como os melhores cenários de efetiva realização dos direitos humanos. 


\section{A ABERTURA CONSTITUCIONAL AOS TRATADOS INTERNACIONAIS DE DIREITOS HUMANOS}

A abertura constitucional aos tratados internacionais, positivada no art. 5 , $\S 2^{\circ}$ da Carta Política de 88 , impõe o dever de considerar a normativa internacional, na medida em que se the reconhece a sua validade legal, e, portanto sendo lei, respeitada deve ser. Tal dispositivo estabelece:

Art. $5^{\circ}, \S 2^{\circ}$ da CF 88: Os direitos e garantias expressos nesta Constituição não excluem outros decorrentes do regime e dos princípios por ela adotados, ou dos tratados internacionais em que a República Federativa do Brasil seja parte. (Grifo nosso)

Com isso, prevê o constituinte uma abertura legislativa dentro do ordenamento jurídico para as regras e princípios provenientes de tratados internacionais, restando discutir qual a potencialidade jurídica de tais normas. Em outras palavras, necessário se faz, situar-se diante das diferentes posições que abordam a hierarquia conferida às regras e princípios previstos em tratados internacionais quando ingressam no ordenamento interno: se possuem força constitucional, legal ou ainda outro status (supra legalidade).

São duas as teses que propõem explicar como ocorre essa interação. Segundo a primeira, adotando uma perspectiva de dualismo jurídico, existem duas esferas independentes de aplicação do Direito: a esfera internacional e a nacional. E na medida em que não há nenhuma intersecção entre elas, não de pode falar em conflito entre suas normas. Afinal, "são esferas que não se tocam, de tal sorte que o ato internacional só opera efeitos se incorporado à ordem interna” (SARLET, 2013, p. 210).

Já a tese do monismo jurídico, afirma que existe apenas um Direito e que ele deve operar de forma coesa, sendo a normativa internacional do direito público e a do direito interno, espécies contidas em um sistema jurídico único. Sendo assim, deverá haver um mé- todo de solução de conflitos normativos que estabeleça quem será o vencedor no eventual conflito entre as duas espécies. "A doutrina brasileira majoritária [com a qual nos filiamos] sustenta a tese do monismo jurídico, com primazia do direito internacional, ou seja, de que o tratado internacional (direito internacional) prevaleceria sobre o direito interno" (SARLET, 2013, p. 210). Neste enfoque, destaca Sarlet

Dentre as conseqüências da afirmação de um monismo com prevalência do direito internacional situam-se duas: (a) o tratado internacional altera a lei interna anterior e/ou a revoga, quando for o caso; (b) o tratado internacional não pode ser alterado por lei superveniente. (SARLET, 2013, p. 210).

Em vista desse cenário de unicidade jurídica e, buscando a coesão do ordenamento jurídico, defende parte da doutrina, com a qual sefilia, que tratados internacionais comuns são equivalentes a leis infraconstitucionais, havendo exceções de supralegalidade, enquanto que tratados internacionais de direitos humanos possuem inegável força constitucional.

Sobre a matéria, detalha ainda Ingo Sarlet (2013, p. 212) que

No que diz respeito à hierarquia dos tratados em relação ao direito interno, uma vez ratificados, obedecem, no Brasil, as seguintes diretrizes:

a) os tratados em geral possuem hierarquia de lei ordinária, prevalecendo a tese da paridade entre tratado e lei;

b) todavia, há hipóteses nas quais não se aplica a regra geral da paridade:

1 - os tratados internacionais em matéria tributária prevalecem sobre as leis, a teor do disposto no art. 98 do CTN, que é expresso neste sentido.

2 - os tratados em matéria de direitos humanos aprovados ratificados antes da EC-45 e/ou não aprovados pelo rito do art. $5^{\circ}, \S 3^{\circ}$, da CF possuem, de acordo com a atual orientação do STF, hierarquia supralegal;

3 - os tratados em matéria de direitos humanos aprovados pelo rito qualificado estabelecido no art. $5^{\circ}, \S 3^{\circ}$, da CF serão equivalentes às emendas constitucionais, 
de tal sorte que terão hierarquia de direito constitucional "derivado", cabendo, no máximo, sua declaração de inconstitucionalidade por violação dos requisitos formais (procedimento do $\S 3^{\circ}$ do art. $5^{\circ}$ ) ou, eventualmente, a prevalecer tal entendimento, por violação das "cláusulas pétreas" da Constituição Federal.

\begin{abstract}
Além das exceções mencionadas, podem ser identificadas outras, designadamente, nos casos de extradição, em face do disposto no art. 82 , $\S \S 2^{\circ}$ e $3^{\circ}$, da Lei $6.815 / 1980$, considera-se que a lei interna cede e face do tratado de extradição, bem como as hipóteses extraídas do art. 178 da CF, com redação que the foi dada pela EC 7/1995 (dispondo sobre o respeito ao acordo internacional sobre a ordenação do transporte internacional), assim como o art. 34 da Lei de Arbitragem (Lei 9.307/1996), dispondo que a sentença arbitral estrangeira será executada no Brasil de acordo com os tratados internacionais.
\end{abstract}

De crucial importância a afirmação feita por Sarlet acerca da posição adotada pelo STF no sentido da diferenciação entre os tratados internacionais de direitos humanos, ratificados antes ou depois da polêmica Emenda Constitucional 45. Entretanto, segue-se com a corrente doutrinária que entende, com o devido respeito à posição adotada pelo STF, que os tratados internacionais de direitos humanos (independente de sua ratificação ter ocorrido antes ou depois da EC/45) têm força constitucional. Isto porque a Constituição tem como fundamento a garantia de Direitos Humanos, evidenciada pelo mandamento constitucional de prevalência dos Direitos Humanos ${ }^{3}$, e ordena, por meio do $\$ 2^{\circ}$ do art. $5^{\circ}$ uma abertura constitucional às regras e princípios adotados em Tratados Internacionais. Aqui corrobora-se posição, a brilhante lição de Flavia Piovesan:

A Constituição de 1988 recepciona os direitos enunciados em tratados internacionais de que o Brasil é parte, conferindo-lhes natureza de norma constitucional. Isto é, os direitos constantes nos tratados internacionais integram e complementam o catálogo de direitos constitucionalmente previstos, o que justifica estender a esses direitos o regime constitucional conferido aos demais direitos e garantias fundamentais. (...)

3. Art. $4^{\circ} \mathrm{A}$ República Federativa do Brasil rege-se nas suas relações internacionais pelos seguintes princípios: [...] II - prevalência dos direitos humanos.
Há que enfatizar ainda que, enquanto os demais tratados internacionais têm força hierárquica infraconstitucional, os direitos enunciados em tratados internacionais de proteção aos direitos humanos apresentam valor de norma constitucional. (PIOVESAN, 2010, p. 58-59).

Assoma-se nesta linha de raciocínio que os princípios e regras derivados de tratados internacionais de direitos humanos devem servir como parâmetro axiológico do ordenamento jurídico, reclamando retomada e aperfeiçoamento por meio da atividade normativa integradora. Ou seja, incidem imediata e plenamente no sistema constitucional, como de igual modo, traduzem propostas e tarefas a serem concretizadas. Trata-se de adotar uma concepção sistêmica do Direito, porém aberta e compreensiva do fenômeno jurídico. Como afirma Jorge Miranda (1991, p. 260):

A uma norma fundamental tem de ser atribuído o sentido que mais eficácia the dê; a cada norma constitucional é preciso conferir, ligada a todas as outras normas, o máximo de capacidade de regulamentação. Interpretar a Constituição é ainda realizar a Constituição.

Com efeito, a realização plena dos mandamentos constitucionais tendo em vista a unicidade constitucional não são dados naturais, mas tarefas a empreender através da interpretação ampla e global que permita realizar o princípio da máxima eficácia constitucional. Nas palavras de Sarlet (2013, p. 227),

Implica o dever do intérprete e aplicador de atribuir o sentido que assegure maior eficácia às normas constitucionais. Assim, verifica-se que a interpretação pode servir de instrumento para assegurar a otimização da eficácia e da efetividade, e, portanto, também da força normativa da constituição.

Logo, a norma constitucional que demanda a primazia dos direitos humanos, somente terá sua máxima eficácia se interpretada, em conjunto e sistematicamente com art. $5^{\circ}, \S 2^{\circ}$, de forma a estabelecer uma hierarquia constitucional para os tratados de direitos humanos ratificados pelo Brasil. 
Tal conclusão articula as duas dimensões de proteção dos direitos humanos: na esfera doméstica e internacional, essenciais em vista da sociedade moderna e globalizada, que não mais suporta uma proteção aos direitos humanos, restrita às fronteiras de cada país. Conforme descreve Cançado Trindade (1991, p. 4) “nos dias de hoje, não há como sustentar que a proteção dos direitos humanos recairia sob o chamado 'domínio reservado do Estado', como pretendiam certos círculos há cerca de três ou quatro décadas atrás".

Trata-se de uma verdadeira hermenêutica de direitos humanos que nasce de "uma confluência entre o direito internacional e o direito público interno, na medida em que constitui objeto tanto de um quanto do outro a extensão ou garantia de proteção cada vez mais eficaz do cidadão, da pessoa humana" (CANÇADO TRINDADE, 1991, p. 623).

\section{DIREITOS HUMANOS E DESENVOLVIMENTO}

Superada essa etapa de caracterização da força constitucional para as normas e princípios constantes em tratados internacionais de direitos humanos ratificados pelo Brasil, enfocamos os direitos econômicos, sociais e culturais (DESC) em seus desafios contemporâneos, como condicionantes do desenvolvimento.

O desenvolvimento é termo há muito utilizado na literatura, e como tal em constante mutação. Considerado, durante largo período como sinônimo de crescimento econômico, assim estabeleceu-se uma relação direta entre os dois: quanto maior o crescimento econômico de uma determinada sociedade, mais desenvolvida ela seria. Por outro lado, outros chegaram a afirmar não haver desenvolvimento, e que isso seria mera ilusão (VEIGA, 2010, p. 17). Posições extremadas tendem a não ser as mais corretas e úteis. Logo, surge a necessidade de uma tese situada no "caminho do meio, ente a miopia que reduz o desenvolvimento ao crescimento, e o derrotismo que o descarta como inexeqüível” (VEIGA, 2010, p. 33).
Segundo Veiga (2010, p. 81),

Desenvolvimento tem a ver, primeiro e acima de tudo, com a possibilidade de as pessoas viverem o tipo de vida que escolheram, e com a provisão dos instrumentos e das oportunidades para fazerem as suas escolhas.

Tal conceituação pode ser complementada pela visão do economista indiano Amartya Sem (2010, p. 17):

\begin{abstract}
0 desenvolvimento pode ser visto como um processo de expansão das liberdades reais que as pessoas desfrutam. 0 enfoque nas liberdades humanas contrasta com visões mais restritas de desenvolvimento, como as que identificam desenvolvimento com crescimento do Produto Nacional Bruto (PNB), aumento de renda pessoais, industrialização, avanço tecnológico ou modernização social. O crescimento do PNB ou das rendas individuais obviamente pode ser muito importante como um meio de expandir as liberdades desfrutadas pelos membros da sociedade. Mas as liberdades dependem de outros determinantes, como as disposições sociais e econômicas (por exemplo, os serviços de educação e saúde) e os direitos civis (por exemplo, a liberdade de participar de discussões e averiguações públicas).
\end{abstract}

O que se infere de novos conceitos como esses demonstrados a respeito do desenvolvimento é a clara falência do pensamento simplista de que desenvolvimento possui um conteúdo unicamente econômico. Entram em cena novos fatores, e assim "a expansão da liberdade é vista por Amartya Sen como principal fim e o principal meio do desenvolvimento" (VEIGA, 2010, p. 34). Logo, as liberdades, no pensamento de Sen, são inerentes à possibilidade de se desenvolver. Em sua linha de raciocínio, somente se desenvolve aquele que tem liberdades, ou seja, que tem escolhas. E somente pode escolher aquele que recebe os meio sociais, culturais e econômicos para tanto.

Portanto, há claramente um conteúdo de provisão social e cultural, além dos econômicos, para que se estabeleçam os parâmetros mínimos responsáveis por solidificar uma estrutura capaz de se desenvolver, garantindo aos cidadãos não somente ganhos 
econômicos, mas, outras possibilidades fartas de escolhas e liberdades.

Ao se conjugar a reflexão, a complexidade que é inerente aos direitos econômicos, sociais e culturais (DESC), deve-se considerar que em países ditos em desenvolvimento, há parcelas da população que são sistematicamente afetadas por uma "concentração de iniqüidades” (IIDH, 1997, p. 68). Significa reconhecer que, via de regra, são os mesmos grupos sociais que estão privados, senão de todos, de importantes núcleos de direitos econômicos, sociais e culturais (DESC).

Partindo de uma conceituação original dos DESC, tais direitos pretendem de um lado, resguardar as pessoas da marginalização do progresso comum da humanidade, e de outro, da exploração que este mesmo progresso tende a gerar. A exclusão social derivada da combinação de carências múltiplas pode ser sintetizada como "déficit de cidadania social” (IIDH, 1997, p. 68), entendido como um déficit de participação da vida coletiva.

Cabe referir que os DESC aludem a obrigações de ação, e não de omissão do Estado, é dizer, pretensões positivas, implicando uma sociedade permanentemente ativa e representada. Daí a visível interrelação e os efeitos recíprocos entre os direitos e liberdade civis e políticas e o direito a acessar um nível mais elevado de bem-estar material e espiritual. Consequentemente, não nos parece aceitável conceber o desenvolvimento econômico sem o pleno respeito dos direitos humanos.

De igual maneira, dificilmente se pode postular a defesa dos direitos humanos sem avanços sustentáveis no tempo, em matéria de bem estar econômico e social.

Em que pese que o acesso aos DESC resulte em algo mais complexo que a prevenção de violações aos direitos civis e políticos das pessoas e comunidades, assegurar o cumprimento do "direito de toda pessoa a um nível de vida adequado para si e sua família, inclusive alimentação, vestimenta e moradia adequadas e uma melhoria contínua de suas condições de vida" ${ }^{4}$ ultrapassa o domínio ético, cultural, político e institucional de uma sociedade e acaba por ingressar no terreno econômico e de geração de recursos suficientes.

Evidencia-se, portanto, a natureza diferenciada dos direitos econômicos, sociais e culturais, se comparados aos direitos civis e políticos, ao menos no tocante à sua exigibilidade que, forçosamente está vinculada à ideia de desenvolvimento, e como tal será por definição gradual e relativa. Contudo, resta cristalina a indivisibilidade dos direitos humanos: a não realização de direitos econômicos, sociais e culturais acaba por impactar nos direitos civis e políticos que, tendem a perder sentido para os setores com poucos recursos e com baixos níveis de educação e informação.

Ademais, está comprovado que tais setores têm um acesso muito mais difícil à justiça e às possibilidades de defender-se de terceiros ou do próprio Estado. Não é novidade que pobreza e cidadania deficitária caminham muitas vezes de mãos dadas. Por último, inversamente, pode-se destacar que a supressão de direitos civis e políticos conduzem à incapacidade de organização social e a própria reivindicação dos direitos econômicos e sociais.

Ao se observa com alguma sistemática e regularidade, os relatórios de acompanhamento da situação dos direitos humanos em países ditos em desenvolvimento, facilmente se confirmará que grosso modo, os avanços obtidos em matéria de direitos civis e políticos não se fazem acompanhar dos correspondentes avanços em DESC, resultando em muitos países em uma piora no exercício de direitos, em seu conjunto.

Quando o Estado de Direito é concebido, também, pelas efetivas condições para o alcance de aspirações legitimas de dignidade, maiores são as razões para

4. Artigo 11 do Pacto Internacional dos Direitos Econômicos, Sociais e Culturais. 
não reconhecer os direitos econômicos, sociais e culturais no plano constitucional interno.

Esta foi a dimensão dada ao Estado de Direito pela Comissão Internacional de Juristas na Declaração de Delhi de 1959:

O Estado de Direito [...] deve ser utilizado não só para garantir e promover os direitos civis e políticos do indivíduo numa sociedade livre, mas também para estabelecer as condições sociais, econômicas, educativas e culturais em que as aspirações legitimas e sua dignidade podem tornar-se realidade.

Mais recentemente, alguns autores consideram esta característica a marca decisiva do processo de transição do Estado de Direito para o Estado Constitucional de Direito.

Na definição de Luigi Ferrajoli (2007), o Estado Constitucional de Direito é um novo modelo de direito e de democracia. Para ele, garantismo e constitucionalismo são faces da mesma moeda, na medida em que ao garantismo corresponde a elaboração e a implementação das técnicas de garantia idôneas para assegurar o máximo grau de efetividade dos direitos constitucionalmente reconhecidos. Além disso, sua concepção do paradigma democrático conduz à garantia de todos os direitos, não somente os direitos de liberdade, como também os direitos econômicos, sociais e culturais. Garantia que se estabelece, também, frente a todos os poderes, não só aos poderes públicos, mas, também, aos poderes privados, e em terceiro lugar, garantia em todos os níveis: doméstico e internacional.

Por tais razões, o futuro do constitucionalismo, assim como da democracia, no entender de Ferrajoli está confiado a uma articulação entre o constitucionalismo social e o liberal, entre o constitucionalismo de direito privado e o de direito público e o constitucionalismo internacional e o nacional. E assim sendo, a história do constitucionalismo pode ser lida como a história de uma progressiva extensão da esfera dos direitos.
Tais considerações corroboram na elucidação do modelo constitucional brasileiro a partir de 1988 e seus efeitos para o desenvolvimento, como processo integrado, que inclui inexoravelmente diversos âmbitos da vida social.

\section{CONSIDERAÇOES FINAIS}

Considerando que dada sua inegável força normativa, a Constituição ordena e conforma a realidade política e social em uma relação de duplo e recíproco efeito, procurou-se destacar como a cláusula de abertura constitucional aos tratados internacionais de direitos humanos, configura um dos elementos de identificação da ordem constitucional brasileira.

Adotando uma perspectiva crítica de que os direitos humanos correspondem às projeções normativas das necessidades reais e concretas que representam potencialidades de desenvolvimento dos indivíduos, grupos e povos. E tendo em vista que se encontram consubstanciados nos instrumentos jurídicos internacionais, é imperioso reconhecer que ingressam no ordenamento jurídico interno com hierarquia constitucional, em razão do que dispõe o próprio texto da Carta Política de 88 , em seu artigo $5^{\circ} \S 2^{\circ}$.

A confluência entre o direito internacional e o direito público interno, configura uma verdadeira hermenêutica de direitos humanos que articula as duas dimensões de proteção dos direitos humanos: na esfera doméstica e internacional, ambas essenciais em vista dos desafios contemporâneos colocados na sociedade moderna e globalizada.

Nessa direção, entendido o desenvolvimento como processo integrado, que inclui inexoravelmente diversos âmbitos da vida social, ou seja, resultado da convergência dos diferentes domínios da vida em sociedade, depreende-se a necessidade de realização dos direitos econômicos, sociais e culturais, como sua condição. 0 que inclui necessariamente seu reconhe- 
cimento constitucional, sua integração ao sistema jurídico interno por meio dos pactos internacionais que Ihes reconhecem e o aperfeiçoamento do sistema de controle constitucional.

A consagração internacional dos direitos humanos, por meio de instrumentos jurídicos específicos adotados internacionalmente e seu reconhecimento na ordem constitucional interna, permitem ler a história do constitucionalismo como a história de uma progressiva extensão da esfera dos direitos. A única chance de ver realizado o desenvolvimento em âmbito global e regional.

\section{REFERÊNCIAS}

ALEXY, Robert. Teoria dos Direitos Fundamentais. 2.ed. São Paulo: Malheiros Editores, 2011

BARATTA, Alessandro. Os direitos da criança e o futuro da democracia. In: Perspectivas do direito no início do século XXI - Studia Jurídica n.41. Boletim da Faculdade de Direito, Universidade de Coimbra. Coimbra: Coimbra, 1999.

BOBBIO, Norberto. A era dos direitos. Tradução de Carlos Nelson Coutinho. Rio de Janeiro: Campus, 1992.

BONAVIDES, Paulo. Curso de Direito Constitucional. 27.ed. São Paulo: Malheiros, 2011

BRASIL. Constituição Federal de 1988. Disponível em: <http://www.planalto.gov.br/ccivil_03/Constituicao/ ConstituicaoCompilado.htm>. Acesso em: 8 jul. 2013 CANÇADO TRINDADE, Antonio Augusto. A proteção internacional dos Direitos Humanos. São Paulo: Saraiva, 1991.

COMPARATO, Fábio Konder. Fundamentos dos Direitos Humanos. Disponível em: <http://www.iea. usp.br/publicacoes/textos/comparatofundamento. pdf/at_download/file>. Acesso em: 15 jun. 2013.
FARIA, José Eduardo. Direitos Humanos, Direitos Sociais e Justiça. São Paulo: Malheiros Editores, 1994.

FARIA, José Eduardo. Direito e Globalização Econômica: Implicações e Perspectivas. São Paulo: Malheiros Editores, 2010.

FERRAJOLI, Luigi. Sobre los Derechos Fundamentales. In: CARBONELL, Miguel. Neoconstitucionalismo(s). Madrid: Trotta, 2003.

HESSE, Konrad. A Força Normativa da Constituição. Trad. de Gilmar Ferreira Mendes. Porto Alegre: Sergio Antonio Fabris Editor, 1991.

IIDH/Instituto Interamericano de Direitos Humanos. La Igualdad de los modernos: reflexiones acerca de la realización de los derechos econômicos, sociales y culturales. San Jose, Costa Rica. (Comisión Econômica para America Latina y El Caribe), 1997.

JACINTHO, Jussara Maria Moreno. Dignidade humana - princípio constitucional. Curitiba: Juruá. 2009.

MIRANDA, Jorge. Manual de direito constitucional. 3.ed. Coimbra: Coimbra, 1991.

OLIVEIRA JUNIOR, José Alcebíades. Teoria jurídica e novos direitos. Rio de Janeiro: Lúmen Júris, 2000.

PIOVESAN, Flavia. Direitos Humanos e o Direito Constitucional Internacional. 11.ed. São Paulo: Saraiva, 2010.

ROSILLO MARTÍNEZ, Alejandro. Derechos Humanos: Liberación y Filosofia de la Realidad Histórica. In: ROSILLO MARTÍNEZ, Alejandro, et al. Teoria Crítica dos Direitos Humanos no Século XXI. Porto Alegre: EDIPUCRS, 2008.

SANCHEZ RUBIO, David. Encantos y Desencantos de los Derechos Humanos: de emancipaciones, liberaciones e dominaciones. Barcelona: Icaria Editorial, 2011. 
SARLET, Ingo Wolfgang; MARINONI, Luiz Guilherme; MITIDIERO, Daniel. Curso de Direito Constitucional. 2.ed. São Paulo: Revista dos Tribunais, 2012.

SCHAPIRO, Mario G. Repensando a relação entre Estado, direito e desenvolvimento. In: VIEIRA, Oscar V.; DIMOULIS, Dimitri. (Orgs.) Estado de Direito e o Desafio do Desenvolvimento. (Coleção Direito, Desenvolvimento e Justiça), São Paulo: Saraiva, 2011.

SEN, Amartya. Desenvolvimento como liberdade. São Paulo: Companhia das Letras, 2010.
SIQUEIRA CASTRO, Carlos Roberto. A constituição aberta e os Direitos Fundamentais. 2.ed. Rio de Janeiro: Forense, 2010.

SILVA, Virgílio Afonso. Direitos Fundamentais: conteúdo essencial, restrições e eficácia. 2.ed. São Paulo: Malheiros Editores, 2010

VEIGA, José Eli da. Desenvolvimento sustentável: o desafio do século XXI. Rio de Janeiro: Garamound, 2010.

VIEIRA, Oscar Vilhena. Direitos Fundamentais: uma leitura da jurisprudência do STF. São Paulo: Malheiros, 2006. 